\title{
Resenha de Vygotsky: a interação no ensino-aprendizagem de línguas
}

Resenha da obra:

FIGUEIREDO, F. J. Q. de. Vygotsky: a interação no ensino-aprendizagem de línguas. São Paulo: Parábola Editorial, 2019.

Neuda Alves do Lago ${ }^{1}$

Faculdade de Letras/Programa de Pós-Graduação em Letras e Linguística, Universidade Federal de Goiás, Goiânia, GO, Brasil

Há apenas 5 meses do seu lançamento, em abril de 2019, pela Parábola Editorial, Vygotsky: a interação no ensino-aprendizagem de línguas teve sua primeira edição esgotada. Um livro há muito esperado nos Programas de Pós-Graduação e nos cursos de graduação da área de Letras e Educação, no Brasil, Vygosty, de Francisco José Quaresma de Figueiredo faz uma ampla cobertura das ideias do pensador russo no campo do ensino e aprendizagem de segundas línguas (L2) ou línguas estrangeiras (LE). Visto que Vygotsky defende que o aprendizado escolar impacta e muda profundamente os processos cognitivos dos seres humanos, entende-se a ênfase dada à sua teoria nos contextos acadêmicos.

O autor, professor titular da Faculdade de Letras da Universidade Federal de Goiás, é professor de graduação e pós-graduação, há vinte e sete anos exercendo a docência e pesquisa. Tem vasta produção bibliográfica envolvendo os assuntos de erro e correção, escrita em LE, questões interculturais na aprendizagem de línguas, teletandem e aprendizagem colaborativa, no qual este seu mais recente trabalho se inscreve. Figueiredo apresenta o livro como resultado de sua "paixão por Vygotsky e por sua genialidade em enfatizar que a interação favorece a aprendizagem e o desenvolvimento cognitivo dos seres humanos", paixão esta visível nos vários estudos seus ali citados. $\mathrm{O}$ autor comanda, atualmente, a Diretoria de Relações Internacionais naquela instituição.

O livro é prefaciado por Laura Miccoli, supervisora do estágio pós-doutoral do autor, o qual resultou no presente livro. A professora da Universidade Federal de Minas Gerais ressalta sua longa e profícua experiência no campo da colaboração no ensino e aprendizagem,

\footnotetext{
${ }^{1}$ Doutora em Letras (UFG), Faculdade de Letras. Orcid: https://orcid.org/0000-0003-0887-9083.

E-mail: neudalago@ufg.br.
} 
ressaltando que "se há alguém que possa escrever com propriedade e conhecimento sobre Vygotsky, esse alguém é Francisco José Quaresma de Figueiredo". A alta qualidade da obra corrobora sua afirmação.

O livro está estruturado em 6 capítulos. O primeiro deles - Vygotsky e sua teoria expõe uma sucinta biodata de Lev Semenovitch Vygotsky, contextualizando sua rica trajetória acadêmica nos campos de história, filosofia, psicologia, literatura, pedagogia e medicina. É apresentada a forma como se deu o desenvolvimento do seu método genético, que enfatizou a relevância crucial do estudo sobre o processo pelo qual se formam as funções superiores. Em seguida, o capítulo discorre sobre os rudimentos da teoria sociocultural vygotskyana, com sua ênfase no papel da cultura e interação social para o desenvolvimento mental. Finaliza com a menção aos fundamentos da teoria da atividade, proposta por discípulos de Vygotsky.

O papel da fala no desenvolvimento cognitivo e social é tratado no segundo capítulo. Ao definir e exemplificar as falas egocêntrica, interior e privada, relacionando-as tanto aos estágios pelos quais passa a criança quanto ao seu uso rotineiro por adultos, o autor explora o viés sociocultural de que a fluidez e dinamicidade do processo de desenvolvimento humano, manifestas nos papéis distintos da fala, são replicadas no contexto de ensino e aprendizagem de L2/LE. É dada especial ênfase ao ensino de surdos e à educação inclusiva, no final do capítulo.

O terceiro capítulo discute os dois pilares centrais da teoria sociocultural: a mediação - uso de instrumentos sociais e culturais para controle, regulação e desenvolvimento das funções psíquicas e do exterior - e a zona de desenvolvimento proximal (ZDP) - lugar onde a aprendizagem se realiza. São apresentadas várias ferramentas e formas de mediação, no contexto educacional, e as onipresentes manifestações da ZDP, sempre que a criança ou adultos, em qualquer contexto de realização de tarefas, contam com o auxílio de outros mais experientes, atingindo patamares que excedem sua atual competência.

O scaffolding é explorado no quarto capítulo. Iniciando com as ideias dos cunhadores da metáfora, Figueiredo discorre sobre as variadas formas em que aprendizes recebem um apoio temporário para a realização de tarefas, visando à autonomia posterior. $\mathrm{O}$ autor ressalta a forma como, na medida em que os scaffoldings vão sendo retirados, há uma redução da ZDP, dado o aumento da capacidade dos aprendizes. Ele apresenta as seis funções do tutor durante o processo de auxílio, ilustrando com dados do seu arquivo pessoal e de colaboradores seus.

O quinto e sexto capítulo exemplificam a teoria sociocultural com uma variada série de investigações científicas no ambiente de aprendizagem e de formação de professores. Naquele, vários estudos sobre a teoria são mostrados no escopo da abordagem baseada em tarefas, na aprendizagem colaborativa de línguas, no uso de jogos em sala de aula, na avaliação dinâmica e na telecolaboração. Neste, são discutidas pesquisas, na perspectiva sociocultural, sobre a forma como os professores pensam e agem como agentes nos contextos educacionais, tanto em interações presenciais quanto telecolaborativas. 
O livro é inovador ao apresentar conceitos complexos mesclados a excertos de material empírico advindos de pesquisas do autor e outros pesquisadores, seus orientandos, no campo da aprendizagem colaborativa. Destaca-se, também, pelo alto teor didático em cada capítulo, ao trazer recomendações e sugestões para um processo de ensino e aprendizagem bem-sucedido. Indubitavelmente, essas seções esclarecem e facilitam, em muito, uma ação pedagógica ancorada na teoria vygotskyana.

A linguagem do livro é clara, convidativa, num primoroso equilíbrio entre jargão científico e dialeto acessível. Há uma ampla cobertura de produções bibliográficas sobre Vygotsky, em nível nacional e internacional, fornecendo aos leitores um acesso organizado aos distintos estudos realizados acerca da sua obra. Os construtos fulcrais da teoria sociocultural são apresentados e ilustrados em uma gama cuidadosamente selecionada de situações de aprendizagem de L2/LE e de formação de professores.

O livro é primordialmente destinado a professores, alunos e pesquisadores interessados nos bons frutos da interação, no âmbito da aprendizagem de línguas. Entretanto, em harmonia com a observação do autor, de que "Vygotsky está em todos os lugares", quaisquer pessoas que busquem conhecimento dos construtos da teoria sociocultural, em estágio propedêutico ou avançado, encontrarão nele uma obra de referência.

\section{Referência}

FIGUEIREDO, F. J. Q. de. Vygotsky - a interação no ensino-aprendizagem de línguas. São Paulo: Parábola Editorial, 2019.

Recebido em: 30/09/2019.

Aceito em: 05/03/2020. 